$\$ 10$ per 1,000 quoted by one firm for medium weight and $\$ 14$ per 1,000 for heavy weight driers. When it is considered that a large part of the material pressed under the old system, using blotters alone, required the use of two blotters between each specimen, it will be seen that a considerable saving is effected in the cost of the drying material as well as in the time required to handle and completely dry the material.

P. L. RICKER

Bureau of Plant Industry

\section{A NEW COLOR VARIETY OF THE NORWAY RAT}

Norway rats with dilute coat color have recently been taken in the vicinity of the University of Pennsylvania. If we may judge from the fact that the nine individuals thus far found are all approximately alike and are distinctly different from the normal type, they probably represent a new Mendelian variety.

The coat is intermediate in color between that of the ordinary dark form and the albino and resembles that of the red-eyed guinea pig. In the guinea pig this color has been shown by Wright to be allelomorphic with albinism and with dilute. As in the guinea pig, the hair of the new rat seems to be without yellow pigment and is dilute black or brown ticked with white.

The eyes look black unless the light is very bright. When the light shines directly into them they appear pink. They are distinctly lighter than the eyes of Castle's red-eyed yellow rats, but darker than those of his pink-eyed yellows.

The new rats are now in the care of the Wistar Institute, where the endeavor is being made to increase the stock and to cross with the color varieties already known.

Data in regard to the distribution of the new form is being collected and will later be published.

The previously known Mendelian varieties in the rat are five: black, hooded, albino and Castle's two yellow varieties, red-eye and pinkeye. This new variety is a non-yellow dilute and may be called ruby-eye.

Phineas W. Whiting

University of Pennsylvania

\section{SYLVESTER AND CAYLEY}

UNDER the portrait with which the editor has adorned my article "Sylvester at Hopkins," in The Johns Hopkins Alumni Magazine of March, 1916, the designation is simply "James Sylvester."

This omits his real name, his family name, the name to which he was born; for his father was Mr. Abraham Joseph, his two sisters were the Misses Joseph. The name by which we know him he chose for himself, following the example of his eldest brother, who early in life established himself in America and assumed the name of Sylvester.

My laborious and critical friend, Professor G. A. Miller, of the University of Illinois, in his recent book "An Introduction to Mathematical Literature," commits the colossal error of representing Sylvester and Cayley as friends together at college, Cambridge chums, whereas Sylvester entered Cambridge in 1831 and Cayley was senior wrangler at Cambridge in 1842, more than a decade later. Sylvester had already in the session $1837-38$ been appointed professor in London University College, and it was in London, but only after the lapse of nearly another decade, in fact in 1846, that Cayley met Sylvester.

George Bruce Halsted

Greeley, Colo.

\section{SCIENTIFIC BOOKS}

Indian Mathematics. By G. R. KAyE. Calcutta \& Simla, Thacker Spink \& Co., 1915. Pp. 73.

Of all the British writers on the history of Indian mathematics at the present time, none is better known or more serious in his purpose than Mr. Kaye. A scholar by nature and, through his connection with the Indian service, placed in an environment which is conducive to the study of the original sources, few men have the opportunities which are his for bringing the mathematical learning of the East to the knowledge of the West.

This being the case, the reader might naturally expect to find in a publication with such a title as this an exhaustive and well- 